\title{
Genomic characterization of a proventriculitis-associated infectious bronchitis coronavirus
}

\author{
Chao-ting Xiao $\cdot$ Ran Liu $\cdot$ Zhu-yuan Song • \\ Min Liao · Ji-yong Zhou
}

Received: 14 March 2009/Accepted: 11 February 2010/Published online: 27 February 2010

(C) Springer Science+Business Media, LLC 2010

\begin{abstract}
Transmissible proventriculitis associated with infectious bronchitis virus (IBV) was at first seen in eastern China in mid-1995, and is now endemic in China. Herein, the complete genome sequence of a proventiculitis-associated infectious bronchitis coronavirus (ZJ971) was sequenced and analyzed. Compared with the genome of the vaccine strain H120, ZJ971 had 54 nucleotide substitutions and a deletion in the $3^{\prime}$-UTR. The substitutions were in the regions of nsp2-nsp5, nsp7, nsp12, nsp13, nsp15, S and N genes, and the untranslating region. The results indicated that ZJ971 could be a variant of IBV strain H120.
\end{abstract}

Keywords Infectious bronchitis virus - Proventriculitis · Complete genome

Proventriculitis has been seen in chickens throughout the world since the early 1970s [1]. However, the causative agent has not yet been definitively established. Both infectious and dietary agents have been implicated as contributing causes [1]. Some studies have reported infectious bronchitis virus (IBV) to be a candidate

C. Xiao $\cdot$ R. Liu $\cdot$ Z. Song $\cdot$ M. Liao $\cdot$ J. Zhou

Key Laboratory of Animal Epidemic Etiology \& Immunological Prevention of Ministry of Agriculture, Zhejiang University,

Hangzhou 310029, People's Republic of China

C. Xiao $\cdot$ R. Liu $\cdot$ Z. Song $\cdot$ M. Liao $\cdot$ J. Zhou $(\bowtie)$

The Key Laboratory of Conservation Genetics and Reproductive Biology for Endangered Wild Animals of Ministry of Education, Hangzhou 310029, People's Republic of China

e-mail: jyzhou@zju.edu.cn

Z. Song

College of Veterinary Medicine, Hunan Agriculture University, Changsha 410128, People's Republic of China etiological agent [2, 3]. In mid-1995, there was an outbreak of disease in the eastern China characterized by a swollen proventriculus and since then this disease has become endemic in China. Several proventriculitis-associated IBV strains have been isolated and analyzed [4-7], but the full genomes of these viruses have not yet been determined. Here, we report the complete genome sequence of the proventriculitis-associated IBV isolate ZJ971 [4, 8].

The entire genome of ZJ971 is 27,627 nucleotides (nt) in length (GenBank accession No. EU714028), with an $\mathrm{A}+\mathrm{T}$ content of $61.8 \%$, excluding the polyA tail, and has the same genomic organization as the classical IBV strain Beaudette [9]. Its $5^{\prime}$-UTR is 528 (1-528) nt in length. Gene 1 (polymerase gene) consists of $19,836 \mathrm{nt}$, encompassing ORF 1a and ORF 1b. ORF 1a is 11,802 nt in length (52912,330) and encodes a polyprotein of 3933 amino acids (aa; polyprotein 1a, pp1a), while ORF $1 \mathrm{~b}$ is $7,959 \mathrm{nt}$ in length (12,405-20,363), and encodes a protein of 2652 aa (pp1b). Gene 2 (spike, S) of ZJ971 is 3,489 nt in length $(20,314$ 23,802 ), and encodes a protein of 1162 aa. There is a $50 \mathrm{nt}$ overlap between the $3^{\prime}$-end of ORF $1 \mathrm{~b}$ and the $5^{\prime}$-end of the $\mathrm{S}$ gene. Gene 3 is $678 \mathrm{nt}$ in length, and contains three ORF: 3a $(23,802-23,975), 3 b(23,975-24,169)$, and the envelope (E) protein (3c, 24,150-24,479). The length of gene 4 (membrane protein, M) is $678 \mathrm{nt}(24,451-25,128)$, with a $29 \mathrm{nt}$ overlap between the $3^{\prime}$-end of the E gene and the $5^{\prime}$ end of the $\mathrm{M}$ gene. There is a non-coding region of $359 \mathrm{nt}$ between the $3^{\prime}$-end of the $M$ gene and gene 5 . Gene 5 contains ORF 5a $(25,488-25,685)$ and 5b (25,682-25,930). Gene $6(25,873-27,102)$ encodes the $N$ protein (409 aa). There is a $58 \mathrm{nt}$ overlap between the $3^{\prime}$-end of $5 \mathrm{~b}$ and the $5^{\prime}$-end of the nucleocapsid (N) gene. The $3^{\prime}$-UTR of ZJ971 is $525 \mathrm{nt}$ long, $205 \mathrm{nt}$ and $20 \mathrm{nt}$ longer than those of strains M41 (AY851295) and Beaudette (NC_001451), respectively. 
The complete genomic sequence of ZJ971 is very similar to that of the vaccine strain H120 (FJ888351), which is widely used in China, with $99.8 \%$ sequence identity, and only 54 nucleotide substitutions and a deletion of three bases in the $3^{\prime}$-UTR detected in ZJ971. The 54 nucleotide substitutions were distributed throughout the genome, two in $5^{\prime}$-UTR, 35 in gene 1, 14 in the $\mathrm{S}$ gene, two in the $\mathrm{N}$ gene, and one in the $3^{\prime}$-UTR. The 35 nucleotide substitutions in gene 1 resulted in 19 amino acids changes, with six in non-structural protein $(\mathrm{nsp}) 2(198 \mathrm{~T} \rightarrow \mathrm{A}, 322 \mathrm{G} \rightarrow \mathrm{D}$, $331 \mathrm{~S} \rightarrow \mathrm{P}, 358 \mathrm{~A} \rightarrow \mathrm{T}, 475 \mathrm{~A} \rightarrow \mathrm{V}$, and $501 \mathrm{~V} \rightarrow \mathrm{I}$ ), three in $\operatorname{nsp} 3(1126 \mathrm{~N} \rightarrow \mathrm{D}, 1489 \mathrm{~N} \rightarrow \mathrm{D}$, and $1910 \mathrm{R} \rightarrow \mathrm{K})$, three in nsp4 $(2348 \mathrm{I} \rightarrow \mathrm{M}, \quad 2498 \mathrm{~N} \rightarrow \mathrm{T}, \quad$ and $2562 \mathrm{R} \rightarrow \mathrm{K})$, two in $\mathrm{nsp5}(2772 \mathrm{G} \rightarrow \mathrm{V}$ and $2879 \mathrm{~A} \rightarrow \mathrm{T})$, two in nsp7 $(3368 \mathrm{E} \rightarrow \mathrm{K}$ and $3418 \mathrm{I} \rightarrow \mathrm{V})$, one in nsp12 $(4488 \mathrm{P} \rightarrow \mathrm{Q})$, one in $\mathrm{nsp13}(4919 \mathrm{P} \rightarrow \mathrm{S})$, and one in nsp15 $(6129 \mathrm{I} \rightarrow \mathrm{M})$. The 14 nucleotide substitutions in $\mathrm{S}$ gene resulted in nine aa substitutions, including seven in the $\mathrm{S} 1$ subunit $(19 \mathrm{~A} \rightarrow \mathrm{V}, \quad 52 \quad \mathrm{I} \rightarrow \mathrm{V}, \quad 118 \mathrm{G} \rightarrow \mathrm{V}$, $122 \mathrm{I} \rightarrow \mathrm{L}, 130 \mathrm{~S} \rightarrow \mathrm{F}, 355 \mathrm{E} \rightarrow \mathrm{Q}$, and 440T $\rightarrow \mathrm{I})$ and two in the $\mathrm{S} 2$ subunit $(1047 \mathrm{~S} \rightarrow \mathrm{F}$ and $1136 \mathrm{R} \rightarrow \mathrm{K})$. The two nucleotide substituions in the $\mathrm{N}$ gene resulted in one amino acid change $(22 \mathrm{~S} \rightarrow \mathrm{P})$. There are eight epitope clusters within the S glycoprotein of IBV strain D207, located between amino acid residues 24-61 (S1D), 132-149 (S1E), 291-398 (S1C/A/B), 497-543 (S1F), 548-574(S2G), and $1095-1118(\mathrm{~S} 2 \mathrm{H})[10,11]$. Three of the nine aa difference between the S proteins of $\mathrm{H} 120$ and ZJ971 were located in these epitope clusters $(52 \mathrm{I} \rightarrow \mathrm{V}, 130 \mathrm{~S} \rightarrow \mathrm{F}$, and $355 \mathrm{E} \rightarrow \mathrm{Q})$.
These findings suggest ZJ971 could be a variant of IBV strain H120, with mutations distributed throughout the genome.

Acknowledgments This study was supported by grants from the Ministry of Science and Technology of the People's Republic of China (Grant No. 2006BAD06A03), from the earmarked fund for Modern Agro-industry Technology Research System (Grant No. nycytx-41), and from the National Science Foundation of China (Grant No. 30625030).

\section{References}

1. T.V. Dormitorio, J.J. Giambrone, F.J. Hoerr, Avian Pathol. 36, 87-91 (2007)

2. M.J. Pantin-Jackwood, T.P. Brown, Avian Dis. 47, 681-690 (2003)

3. M.J. Pantin-Jackwood, T.P. Brown, G.R. Huff, Avian Dis. 49, 352-360 (2005)

4. J.Y. Zhou, L. Yu, J. Hong, W.C. Ye, Z.Y. Zhang, J. Zhejiang Agric. Univ. 24, 637-641 (1998)

5. G.Q. Zhu, Y.K. Wang, L.S. Sun, J.H. Zhou, G.H. Zhuang, J. Jiangsu Agric. Coll. 17, 55-59 (1996)

6. L. Yu, Y. Jiang, S. Low, Z. Wang, S.J. Nam, W. Liu, J. Kwangac, Avian Dis. 45, 416-424 (2001)

7. J. Pan, D. Chen, Y. Dai, P. Chen, Chin. J. Vet. Sci. Technol. 30, 7-9 (2000)

8. J.Y. Zhou, Acta Vet. Zootech. Sin. 31, 229-234 (2000)

9. M.E. Boursnell, T.D. Browdn, I.J. Foulds, P.F. Green, F.M. Tomley, M.M. Binns, J. Gen. Virol. 68(Pt 1), 57-77 (1987)

10. G. Koch, L. Hartog, A. Kant, D.J. van Roozelaar, J. Gen. Virol. 71(Pt 9), 1929-1935 (1990)

11. A. Kant, G. Koch, D.J. van Roozelaar, J.G. Kusters, F.A. Poelwijk, B.A. van der Zeijst, J. Gen. Virol. 73(Pt 3), 591-596 (1992) 